\title{
Effect of Vibrating Footing on a Nearby Static - Load Footing
}

\author{
Saif K. Ibrahim ${ }^{a^{*}}$, Waad A. Zakaria ${ }^{\mathrm{b}}$ \\ ${ }^{a}$ M.Sc. Student, College of Engineering, University of Diyala, Baqubah, Daiyla, Iraq. \\ ${ }^{b}$ Assist. Prof, College of Engineering, University of Diyala, Baqubah, Daiyla, Iraq. \\ Received 21 April 2019; Accepted 28 July 2019
}

\begin{abstract}
This paper presents an experimental study on the dynamic response of square footings under effect of dynamic load comes from adjacent footing called the (source of vibration) which is excited by a known vibration source placed on the top of it, the objective is to study the effect of dynamic motion of the source of vibration on a nearby footing, called second footing, both footings rest on collapsible soil (gypseouse soil) with gypseouse content (60\%). The study is performed through wide experimental program in dry and soaked condition. The first footing (source vibration) and the second footing have dimensions $(80 \times 80 \times 40),(100 \times 100 \times 40) \mathrm{mm}$ respectively and are manufactured from steel, then the two footings placed centrally over soil after prepared it in layers' form in steel container with $(1000 \times 500 \times 500) \mathrm{mm}$. The first footing exposed to vertical harmonic loading by using a rotating mass type mechanical oscillator to gives a similar effect of the dynamic loads, the second footing loaded with static weight only, under the dynamic excitation. The tests are conducted under dynamic response for three frequencies $(10,20,30) \mathrm{Hz}$, the movement (displacement amplitude, velocity, and acceleration) of the second footing studied by varying spacing between the footings. The results showed that the amplitude of displacement, velocity, and acceleration for the second footing decreases when the spacing between footing increase. In addition, the value of these parameters at dry state is greater than its value at soaked state.
\end{abstract}

Keywords: Dynamic Load; Machine Foundation; Model Test; Square Footing; Vibration.

\section{Introduction}

The Dynamic loads can be generated from moving vehicles, heavy machines, or by move the train, etc. which causing the foundations to behave in a various mode under these loads. The problem of interaction between nearby foundations is of preponderant practical importance, as in many status foundations confront in fact are not secluded and they predominating interact with each other depending on of their close spacing, which may oftentimes be causing damage to structures in both strong and serviceability especially, under dynamic condition. Because of that, a need is to take out a simplified method to study the effect of foundations subjected to dynamic excitement on adjacent foundations. For single isolated foundation many researchers conducted a number of studies onset from the (simple spring-mass-dashpot) system to the (rigorous elastic half space model) proposed by many researchers like [1-3]. Analytical and numerical studies conducted to understand the dynamic interaction of foundations in a group and the soil-structure interaction behavior under dynamic loading such as [4-6].

The gypseous soil is one type of the collapsible soils; it covers wide areas in Iraq. This soil has high bearing capacity in dry state, but it subsides (collapses) upon saturation due to dissolving of cementation and particle bonding. Therefore, structures supported on unstable soil should be guarded against such danger. These problems are usually have led to

* Corresponding author: saifen87@gmail.com

http://dx.doi.org/10.28991/cej-2019-03091367

(C) 2019 by the authors. Licensee C.E.J, Tehran, Iran. This article is an open access article distributed under the terms and conditions of the Creative Commons Attribution (CC-BY) license (http://creativecommons.org/licenses/by/4.0/). 
cracking, tilting and collapsing the related structure [7]. This type of soil covers about $31.7 \%$ in Iraq with different gypsum content ranging from $10-70 \%$ [8].

Chen (2015) researched the cross-cooperation issue among multi-establishments on a straight viscoelastic medium at little shear strains. In the examination, the establishments are discretized into various sub square-components. The dynamic reaction inside each sub-component is depicted by the Green's capacity. Consolidating the removal limit condition and the power balance of the establishments, it gets the dynamic impedance and consistence elements of the establishments. Broad outcomes for two unbending roundabout establishments put at various detachments are introduced. Parametric investigations are done on the dynamic collaboration among adjoining establishments and illustrative the outcomes for a few firmly dispersed establishments [9].

Abhijeet and Priyanka (2016) examined the dynamic cooperation impact of firmly separated square establishments under machine vibration through an exploratory examination, number of enormous scale model tests were directed in the field, the dynamic association of various blends of two-balance get together was researched by actuating vertical symphonious burden on one of the footings (dynamic balance), where the other balance (uninvolved balance) was stacked with the static weight as it were. The dynamic balance was energized with various sizes of dynamic stacking and the reaction was recorded for both the footings, set at various clear separating $(\mathrm{S})$.

They were seen that the inactive balance experiences reverberation because of the dynamic excitation on the dynamic balance, which happens, notwithstanding, with a stage slack from the resounding recurrence of the dynamic balance. This stage slack is observed to be an indispensable parameter in characterizing the dynamic collaboration of a gathering of footings. The stage slack is seen to diminish with abatement in the dispersing between the footings, the variety of transmission proportion is by and large connected with a base and a most extreme point [10].

Chen (2016) performed parametric investigation on the dynamic cooperation between neighbouring establishments. The impacts of separation and arrangement course between establishments have been analysed. He detailed that the consequences of establishments adjusted along various heading showed that the impedance capacities because of the comparing loads on the establishment itself, change pretty much nothing. The coupling impedance works because of the relating loads on different establishments, are emphatically influenced by the establishment arrangement heading. The impedance of an establishment in an establishment bunch at bigger recurrence and separation will in general be that of single establishment [11].

Sbartai (2016) directed an examination on the dynamic cooperation for two neighboring unbending establishments implanted in a viscoelastic soil layer. The technique which has been utilized is the limit component strategy (BEM) to define the arrangement, at that point to deciding the consistence elements of the two adjoining establishments concerning their dispersing, substratum profundity, masses, shapes, installing, load force, and frequencies of excitation. The examination of the exhibited investigation showed that the impact of a few parameters on the dynamic communication reaction of two nearby establishments is no immaterial. Specifically, the predominant impact of certain parameters, for example, the heterogeneity of the dirt, state of the establishments, and the heap force, contrasted with different ones is plainly uncovered [12].

Keawsawasvong and Teerapong (2017), researched the dynamic communication between two inflexible rectangular establishments and a multi-layered poroelastic medium exposed to time-symphonious vertical stacking, it accepted the contact surface between the establishment and the layered medium to be smooth and completely penetrable, and the contact surface was discretized into various square components. It is discovered that the impedance capacities are obviously impacted by the recurrence of excitation and the separation between the two establishments [13].

Han et al. (2017) explored the dynamic association between at least two adjoining establishments laying on the outside of a stratified soil. Parametric investigation was done to explain the impacts of layer profundity, soil damping, dividing between adjoining establishments, masses and minute in activities of supporting structures and the wave engendering speed on the dynamic conduct of three-dimensional (3D) establishment soil-establishment communication (FSFI). Likewise, numerical precedents are given to confirm the exactness and computational dependability of the proposed methodology. He referenced the interfaces between the establishments and the dirt should be discretized and there is no restriction on the thickness or on the quantity of soil layers to be considered and study demonstrated the numerical outcomes got are exceptionally precise [14].

Ali et al. (2018) displayed the aftereffects of the dynamic investigation of a four-chamber blower establishment. The establishment square backings a four-chamber dress-rand blower, suction and release bottles. What's more, by utilizing a three-dimensional limited component model of the dirt establishment framework to decide the dynamic reaction of the dirt establishment framework and to survey the establishment reaction under the connected powerful stacking forced by the blower wrench. The dynamic examination is performed by (1) performing eigenvalue investigation of the establishment square, considering the impact of the dirt establishment connection to decide the dirt establishment characteristic frequencies and modular support variables, and (2) performing constrained reaction of the establishment 
under connected crankshaft unbalance burden to decide the constrained reaction adequacy of the dirt establishment framework [15].

Vicencio and Nicholas (2018) assessed the impact of Structure-Soil-Structure Interaction (SSSI) between two structures given various parameters of the structures, between structure dispersing, and soil type. He proposed a twodimensional straightforward discrete nonlinear model and depicted this by a lot of nonlinear differential conditions of movement. The outcomes demonstrated that there are both horrible and helpful setups of the two structures that produce significant contrasts between nonlinear SSSI and nonlinear SSI (the uncoupled structure case). He referenced that the unfavourable impacts of SSSI can be increasingly articulated when the nonlinear soil conduct is accepted [16].

Andersen (2018) examined the significance of dynamic structure-soil-structure association (SSSI) for structures with at least two establishments, it led the investigation of such polypod establishments in recurrence space, thinking about the range $(0-50) \mathrm{Hz}$ and utilizing Green's function for wave engendering in layered soil. The standardized powerful solidness' identified with individual establishments and cross-coupling between two establishments are introduced [17].

Keawsawasvong et al. (2019), exhibited an examination on the dynamic association issue including firmly dispersed establishments under shaking vibrations. It is discovered that shaking vibrations of the stacked establishment could be considered as a solitary establishment when the separation between the contiguous establishments is twice more noteworthy than their width. Despite what might be expected, an emptied establishment would in any case experience a transmitted vitality disseminated from a stacked establishment notwithstanding when the separation between them increments [18].

Therefore, lack of experimental studies on the behavior of foundation which are adjacent to the machine foundations encouragement to take up the present's investigation, that gives an explanation of the dynamic interference effect between two closely spaced square footings resting on gypseouse soil by conducting small scale model experimental.

The development in the cities as a result of the urgent need to use machines and equipment, and these devices are considered as main sources of vibrations which transfer through soil and effect on their engineering properties. So the objectives of the current work are investigating experimentally the dynamic response of foundation resting on a gypseouse sandy soil under the effect of dynamic load installed on the adjacent foundation in both state (dry and socked). The dynamic response includes displacement amplitude, velocity of vibration, and the acceleration.

This paper presents a study on dynamic response of one footing with static load nearby another footing with dynamic load as (source of vibration) and dynamic loading applied on top of it, both footing have square shape, on a gypseouse soil. The present's investigation deals with the effect of the vibrations of the first footing on the neighboring footing. Both foundations are resting on surface soil.

\subsection{Definition of Problem}

Two closely spaced square placed on gypseouse soil (in both state dry and soaked) as shown in Figure 1. The load intensity below the first footings (source of vibration) was maintained as $\left(6 \mathrm{kN} / \mathrm{m}^{2}\right)$, the second footing is placed with intensity of load equal to $\left(30 \mathrm{kN} / \mathrm{m}^{2}\right)$ and (S) represents the spacing between the two footings. The objective is to determine the dynamic response of the second footing (displacement amplitude, velocity, acceleration), due to the application of dynamic excitation on the top of the first footing.

$\mathbf{L}$

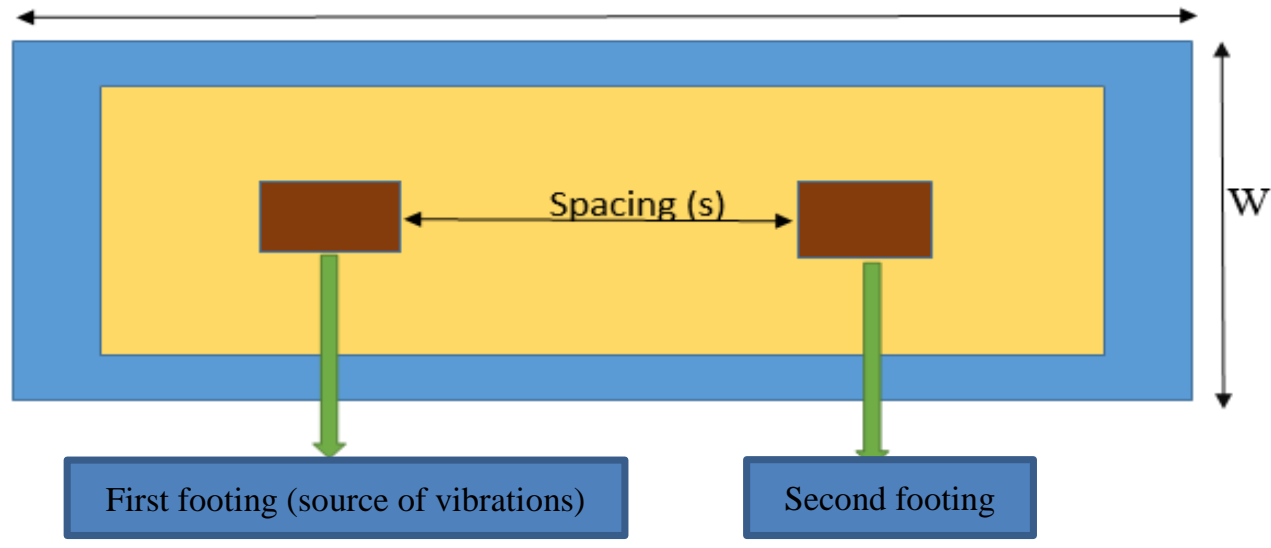

Figure 1. Layout of experimental model 


\section{Materials and Methods}

\subsection{Apparatuses of Model}

The apparatuses of model include the followings:

1) Steel box with dimension $(1000 \times 500 \times 300) \mathrm{mm}$.

2) Two footings with dimensions $(80 \times 80 \times 40) \mathrm{mm}$, for first footing as a machine foundation, (100x100x40) mm, for second footing which manufactured from steel

both footings have square shape.

3) Mechanical oscillator.

4) Piezoelectric accelerometer.

5) Two dial gauge.

6) Variable frequency drive.

7) Vibration meter.

8) Digital tachometer.

9) Computer device.

10) Steel Mold.

11) Water tank.

12) Dial gauge.

13) Static weight.

14) Ac automatic voltage regulator.

15) Camera stand

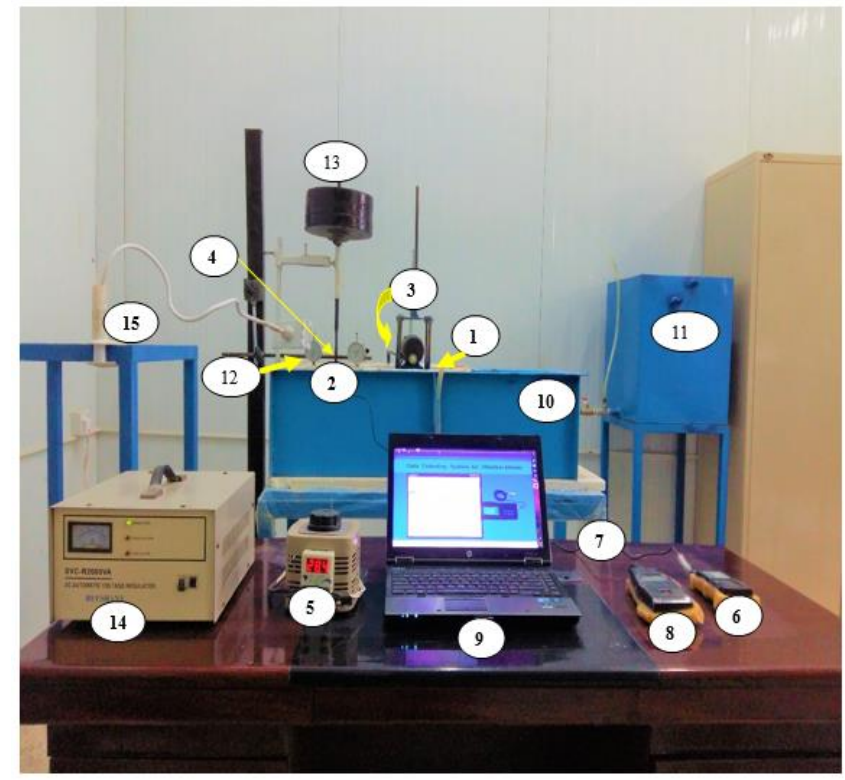

Figure 2. The model with apparatuses

\subsection{Test Setup}

After reviewing the previous studies presented by various researchers, such as [19 -24], the experimental model setup was designed, on the analysis of foundations under effect of the harmonic vibrations. A two steel square footings, the first with dimensions (100x100x40) $\mathrm{mm}$ as a machine foundation (vibration source), the second footing with dimensions (80x80x40) $\mathrm{mm}$ subjected to static load only. Circular weights (20kg in mass) of $25 \mathrm{~cm}$ in diameter used for loading the second footing statically, a rotating mass mechanical oscillator instead over the first footing to produce a varying dynamic load. The mechanical oscillator be composed of a rotating discs made from steel, with diameter (60) $\mathrm{mm}$ and, thickness (10) mm. A small eccentricity mass (me) is put on rotating disc at an eccentricity (e) of (20) mm, from the axis of rotation. In this study, one type of eccentric settings is used with value (60) $\mathrm{gm}$.

A varying speed DC motor is used to turn on the (mechanical oscillator) at different frequency with ranging from (100rpm - 11000) rpm. A speed controller unit is placed outside the model to control the speed of the DC motor.

The Piezoelectric accelerometer which was connected directly to computerized digital vibration meter (6063) model, which was in turn interfaced to the computer for displaying the dynamic response as displacement amplitude, velocity or acceleration is set before the test.

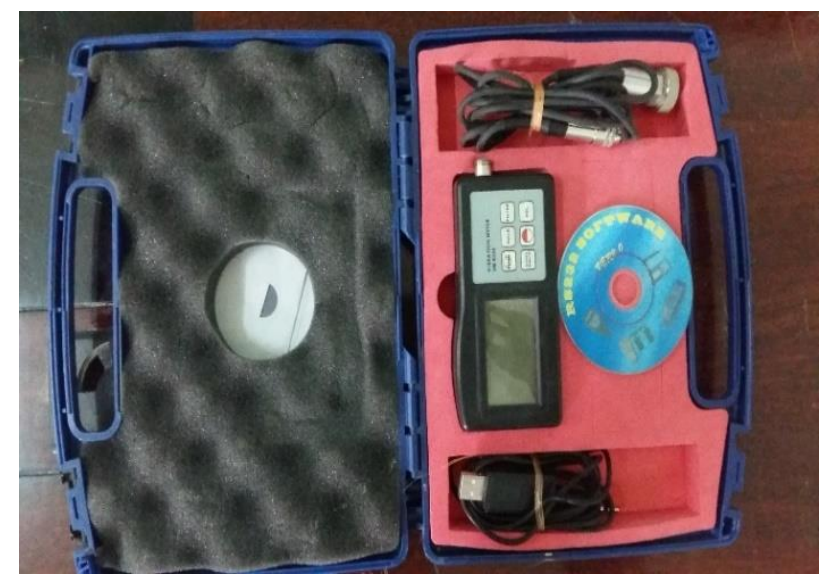

Figure 3. Devices used for measuring vibration response

The digital tachometer (DT-2234A+) model was used to ensure that there is no change in the frequencies. Two-dial gauge are used to determine the settlement of the second footing during operation model by Place them on the edges of the footing. 


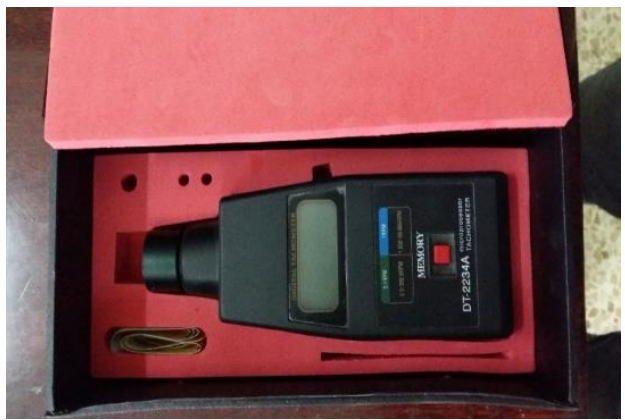

Figure 4. Digital tachometer

\subsection{Preparation and Test Procedure}

The soil in this research was taken from Governorate located north of Iraq, namely Tikrit, has been carried out for the testing program; see Figure 5. Table 1 shows the physical properties of the soil and Table 2 shows the chemical properties. Figures 6 and 7 revealed the results of the laboratory tests carried out on the soil sample used in current study. Water content test is conduct at temperature $(45){ }^{\circ} \mathrm{C}$ to prevent losing crystal of gypseous soil. The sample of gypseous soil of gypseouse content of (60\%) are classified as moderately severe (ASTM D5533-2003). The gypseous soil (passing sieve no.4) placed in the steel container in six layers with a uniform field density using the hummer device. The surface checked and leveled by a bubble ruler (balance) device. Both footings are placed centrally over the prepared soil.

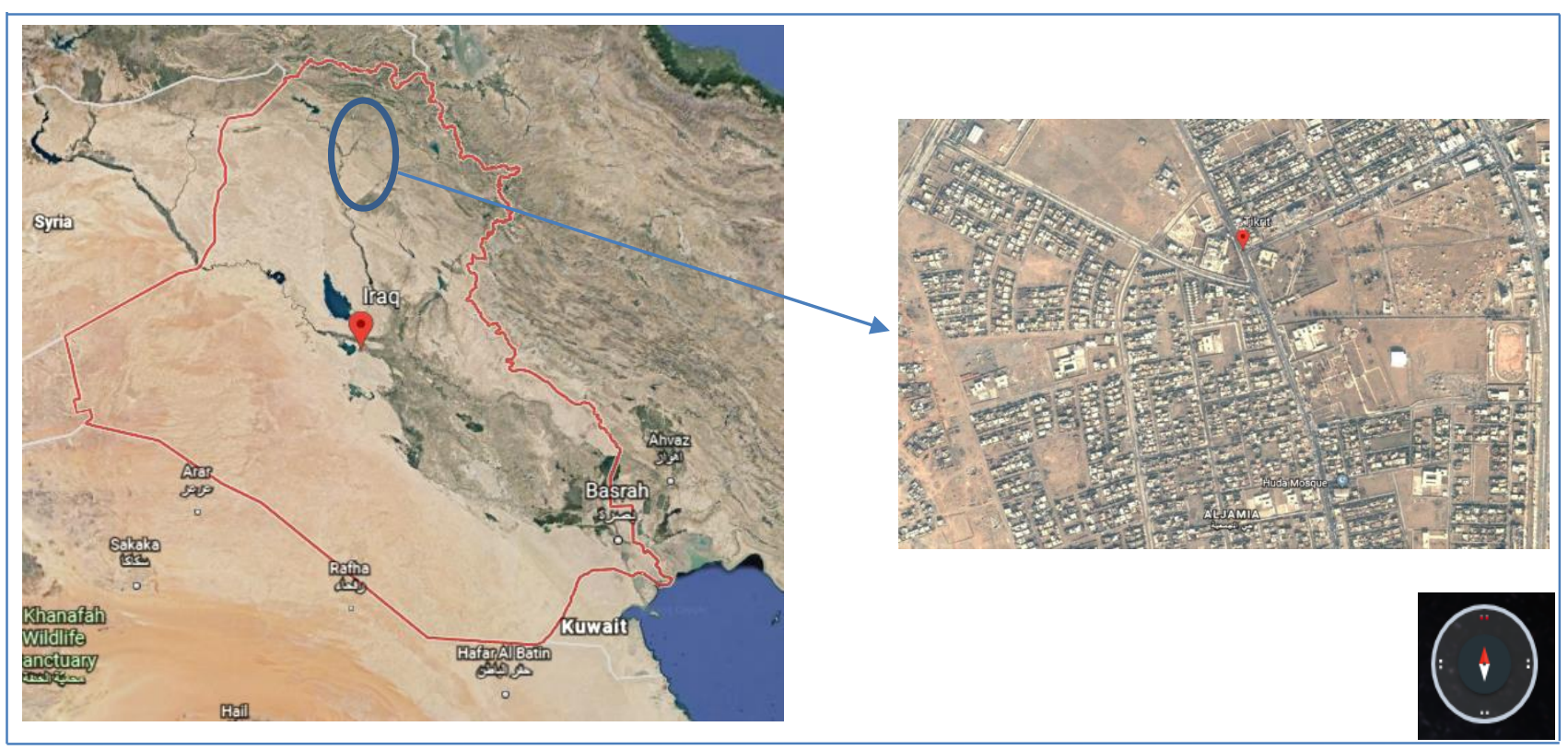

Figure 5. The location of the soil sample

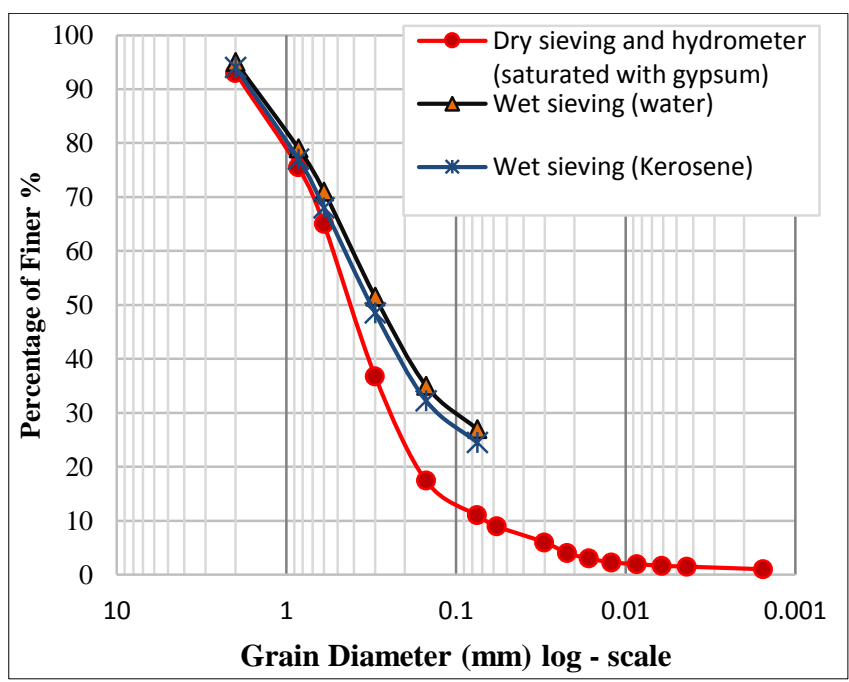

Figure 6. Grain size distribution for gypseous soil

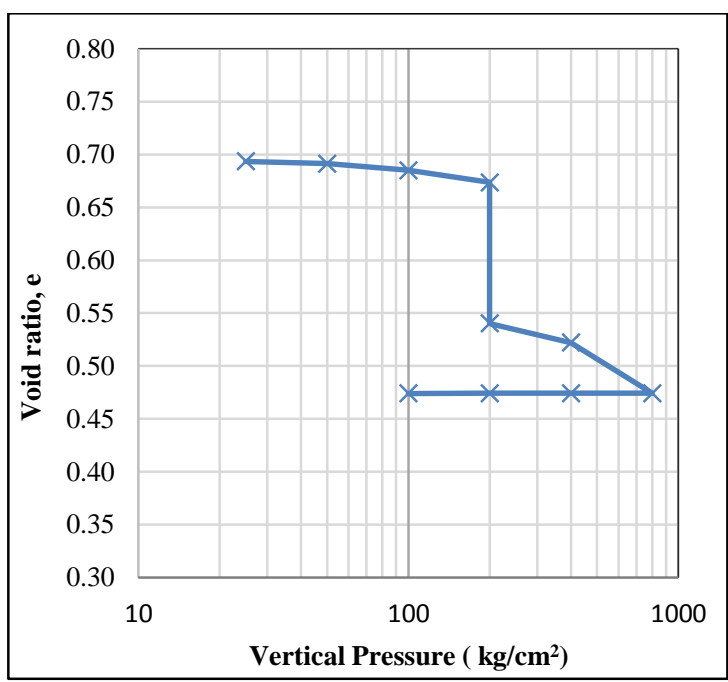

Figure 7. Results of single oedometer collapse test for sample soil used 
Table 1. Physical property of gypseous soil which is used for testing

\begin{tabular}{|c|c|c|c|}
\hline Test & Properties & Value & Specification \\
\hline & Specific Gravity (Gs) & 2.41 & ASTM D 854 (2006) \\
\hline \multirow{3}{*}{ Atterberg's limits } & Liquid limit (L.L) \% & 21.1 & \multirow{3}{*}{ ASTM D4316-84 } \\
\hline & Plastic limit (P.L) \% & N.P & \\
\hline & Plasticity Index (P.I) & N.P & \\
\hline \multirow{3}{*}{ Compaction characteristics } & Max. dry density $\left(\mathrm{KN} / \mathrm{m}^{3}\right)$ & 16.23 & \multirow{2}{*}{ ASTM 698-00 } \\
\hline & Optimum Moisture content $\%$ & 12.33 & \\
\hline & Water content $\%$ & 2.8 & ASTM D2216-02 \\
\hline \multirow{8}{*}{ Grain size analysis } & $\mathrm{D} 10(\mathrm{~mm})$ & 0.07 & \multirow{7}{*}{ ASTM D422-02 } \\
\hline & $\mathrm{D} 30(\mathrm{~mm})$ & 0.14 & \\
\hline & $\mathrm{D} 60(\mathrm{~mm})$ & 0.35 & \\
\hline & Coefficient of uniformity, $\mathrm{Cu}$ & 5 & \\
\hline & Coefficient of curvature, $\mathrm{Cc}$ & 0.8 & \\
\hline & Passing sieve No. 200 (\%) (using kerosene) & 24 & \\
\hline & Classification of soil based on (USCS) & SM & \\
\hline & The collapse potential & 7.9 & ASTM D5533-2003 \\
\hline \multirow{6}{*}{ Direct Shear Test } & Angle of Internal Friction (Ø) in dry & 38 & \multirow{4}{*}{ ASTM D 3080-98 } \\
\hline & Soil Cohesion $(\mathrm{C})\left(\mathrm{KN} / \mathrm{mm}^{\wedge} 2\right)$ in dry & 14 & \\
\hline & Angle of Internal Friction $(\varnothing)$ in soaked & 34 & \\
\hline & Soil Cohesion $(\mathrm{C})\left(\mathrm{KN} / \mathrm{mm}^{\wedge} 2\right)$ in soaked & 5 & \\
\hline & Test unit weight $(\mathrm{kN} / \mathrm{m} 3), \gamma \mathrm{d}$ test & 15 & \\
\hline & Field density $((\mathrm{kN} / \mathrm{m} 3), \gamma$ field & 14.6 & ASTM D1556-07 \\
\hline
\end{tabular}

Table 2. Results of chemical properties of gypseous soil used for testing (BS 1377: 1990, Part 3)

\begin{tabular}{lc}
\hline Composition & Value \% \\
\hline Total soluble salts (T.S.S.) \% & 67.2 \\
Gypsum content \% & 60 \\
Sulphate content (SO3) \% & 30.5 \\
Organic matters (O.M) \% & 0.22 \\
Chloride content (CL) \% & 0.062 \\
pH value & 8.1 \\
\hline
\end{tabular}

Proper care is taken to keep the center of gravity of system and the footings to lie in the same vertical line with center of gravity of the container. After studying results reached by the researchers and carried out some preliminary tests, time of one hour for the duration of the tests chosen, 30 minutes' operation test for the dry state and 30 minutes for the test under soaking condition, it is important to mention that for the test under soaking condition, steel container left for (24) hours to be sure that soil was completely soaked, and in the second day the test is continue.

In this investigation, eccentric settings $(\mathrm{me}=60 \mathrm{gm})$ is used to simulate dynamic load. The oscillator is then operated slowly through a motor by using speed control unit to prevent sudden application of high dynamic load. Thus, the first footing subjected to vibration in the vertical direction.

The dynamic response (displacement amplitude, velocity, acceleration) of the second footing are measured and recorded at the same time using Piezoelectric accelerometer and two dial gauge, are placed, previously on top and edge of the second footing to obtain a foundation response, the operating frequency of $(600,1200,1800)$ rpm equivalent to $(10,20,30) \mathrm{Hz}$ is considered in the present study, the response parameters were recorded every 5 minutes during operation test duration. 


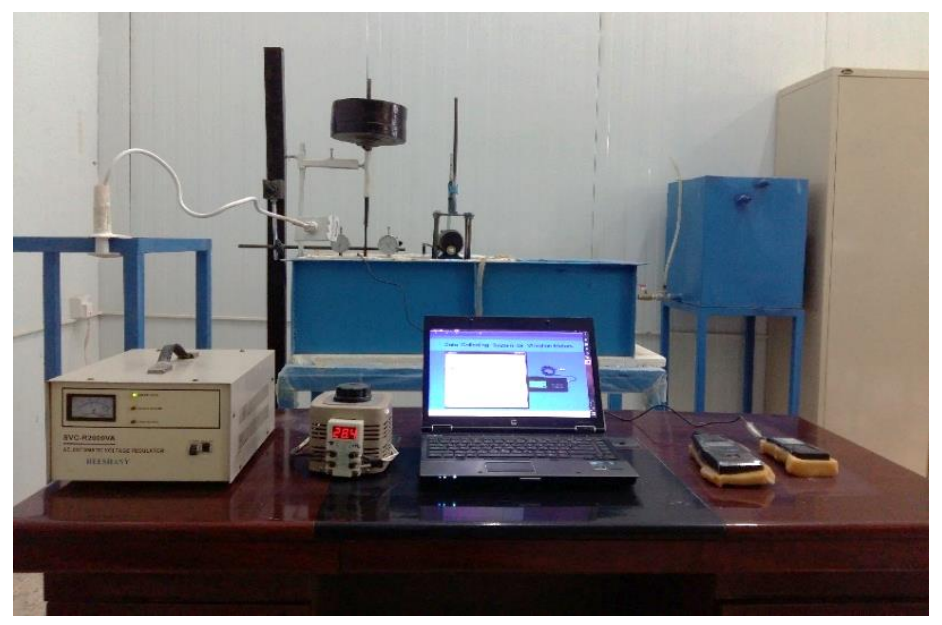

Figure 8. Laboratory Model Testing

\section{Results and Discussion}

In the present study, the dynamic response of square footing is investigated under dynamic exciting force which originated from a nearby footing as a machine foundation.

After verifying the stability of foundations under the static load, the dynamic analysis for the second footing is carried out by exciting the first footing with vertical load intensity created by the machine vibration. The displacement amplitude, velocity, and acceleration at different spacing between the two footings $(S=B, S=2 B, S=3 B$ ) are measured which the two footings are erected on gypseouse soil for both state (dry and soaking) in presence of the dynamic excitation applied on the first foundation. The dynamic response of the second footing for three frequencies $(10,20,30)$ $\mathrm{Hz}$ at different spacing between footings is shown in Figures 9-14.

\subsection{Displacement Amplitude}

In Figures 9 and 10 the maximum and minimum displacement amplitude plotted against the frequency, for three frequencies (as mentioned above) at dry and soaking state, we note that the magnitude of the displacement amplitude at $(\mathrm{S}=\mathrm{B})$ increases when the operation frequency increases for both state (dry and soaking). For the maximum amplitude at dry and soaking state, this increasing is slight when goes from $10 \mathrm{~Hz}$ to $20 \mathrm{~Hz}$ and be larger when goes to $30 \mathrm{~Hz}$. On other hand, the minimum amplitude shows increases just slightly when goes form $10 \mathrm{~Hz}$ to $20 \mathrm{~Hz}$ or $30 \mathrm{~Hz}$ at dry state but at soaking, its doubled in value.

At soaking state, it is observed that there is a decreasing in magnitude of the displacement amplitude compare with dry state for the three frequencies, this decreasing after soaking can be attributed to presence of water, whom acting as a wave inhibitor. The energy of the vibrations generated from the first footing became lower during transmission through soil at soaking condition causing decreasing in the displacement amplitude of the second footing.

At $(S=2 B)$, here finds decreasing in values of the maximum and minimum displacement amplitude compare with magnitude of the displacement amplitude at $(\mathrm{S}=\mathrm{B})$ for both state (dry and soaking). This is because the wave of vibration cut off a longer distance when it travels from the source (the first footing) to the receiver (the second footing). In other word, increasing the spacing led to decreases the displacement amplitude, the propagated of vibrations through the soil leads to a decrease in the energy of those vibrations.

At ( $\mathrm{S}=3 \mathrm{~B}$ ), for the maximum displacement amplitude at dry state, the magnitude increased by half when goes from $10 \mathrm{~Hz}$ to $20 \mathrm{~Hz}$ and increased by two and a half times in value at $30 \mathrm{~Hz}$. For the minimum displacement amplitude, the value has doubled from $10 \mathrm{~Hz}$ to $20 \mathrm{~Hz}$ or $30 \mathrm{~Hz}$. 

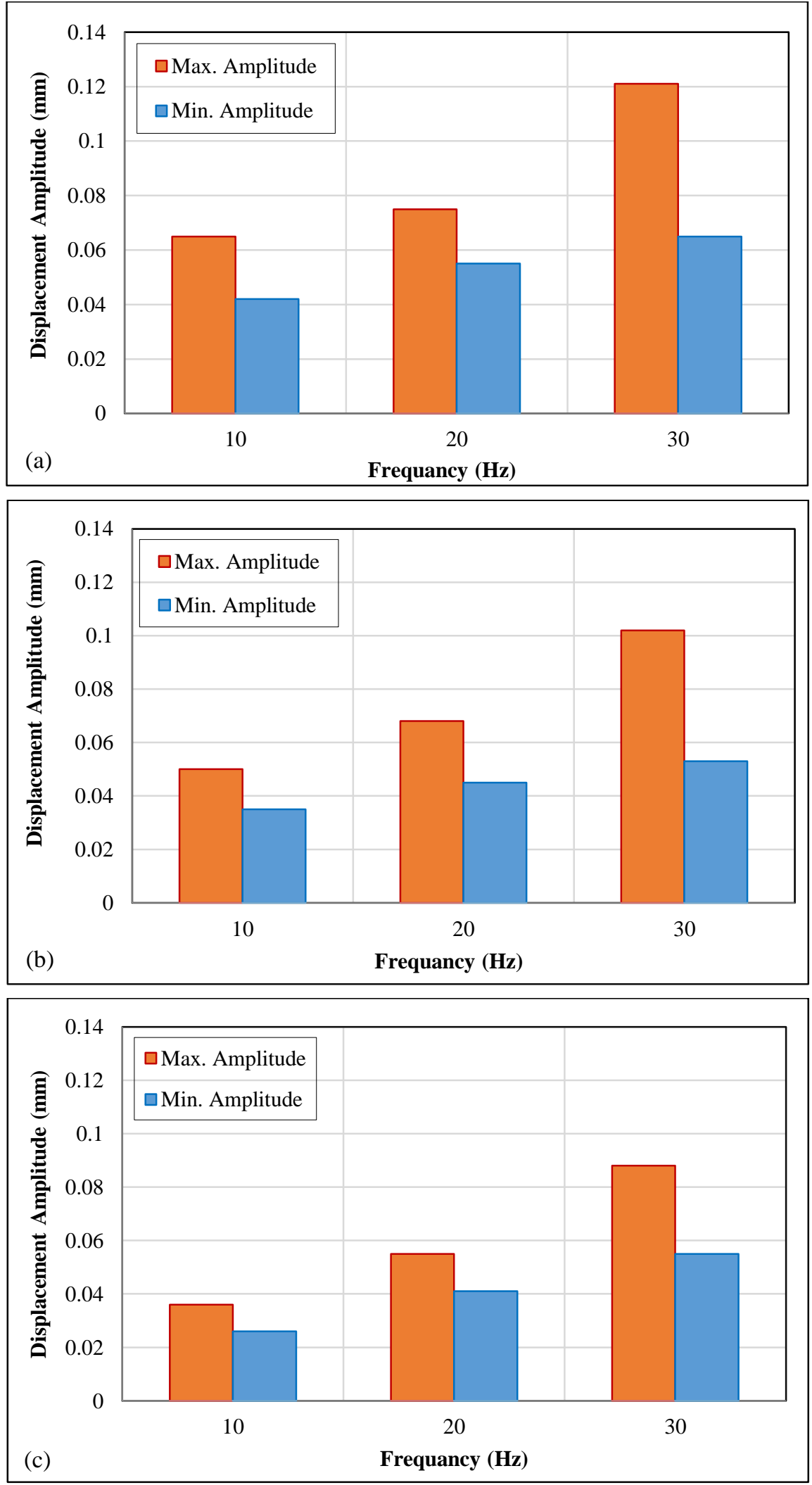

Figure 9. The displacement amplitude versus frequency for different spacing (s), (a) at $S=B$, (b) at $S=2 B$, (c) at $S=3 B$ for dry condition

At soaking state, there is a decreasing in magnitude of displacement amplitude compare with dry state. The maximum displacement amplitude shows slight increase when goes from $10 \mathrm{~Hz}$ to $20 \mathrm{~Hz}$, but doubled in magnitude when moves to $30 \mathrm{~Hz}$. The minimum displacement amplitude shows different behavior, the magnitude of amplitude increases doubled when goes from $10 \mathrm{~Hz}$ to $20 \mathrm{~Hz}$ and increased by three times in value at $30 \mathrm{~Hz}$.

Here observes the magnitude of the displacement amplitude decreased in comparison with magnitude amplitude at $(\mathrm{S}=\mathrm{B})$, and $(\mathrm{S}=2 \mathrm{~B})$ for both state (dry and soaked). 

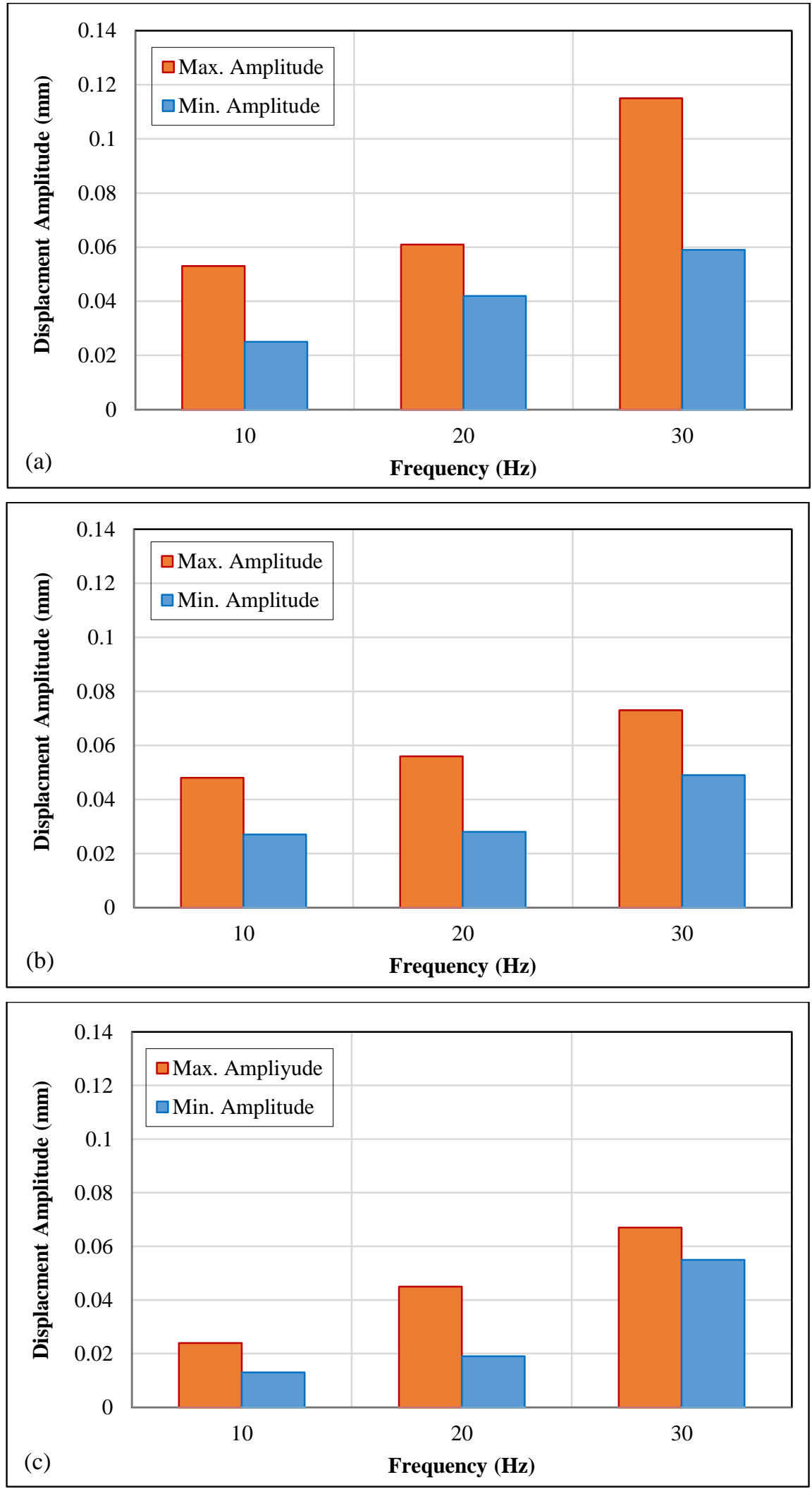

Figure 10. The displacement amplitude versus frequency for different spacing (s), (a) at $S=B$, (b) at $S=2 B$, (c) at $S=3 B$ for soaked condition.

As a result, it can mention the general remarks as followings:

- The displacement amplitude at soaked state less than the displacement amplitude at dry state for all frequencies.

- The displacement amplitude, increase when frequency increase, regardless whether the state is wet or dry.

- As a logic, the maximum displacement amplitude reduced when the spacing between the two footings increase, in both soaked and dry specimen. 


\subsection{Velocity of Vibrations}

Figures 11 and 12 show the relationship between the maximum and minimum velocity versus the frequency which are recorded for three spacing $(\mathrm{S}=\mathrm{B}, \mathrm{S}=2 \mathrm{~B}, \mathrm{~S}=3 \mathrm{~B})$ on dry and soaked soil basis, it can be seen that maximum and minimum velocity diverge with increases of frequency, and converge with increased of spacing between the two footings for both state (dry and soaked).
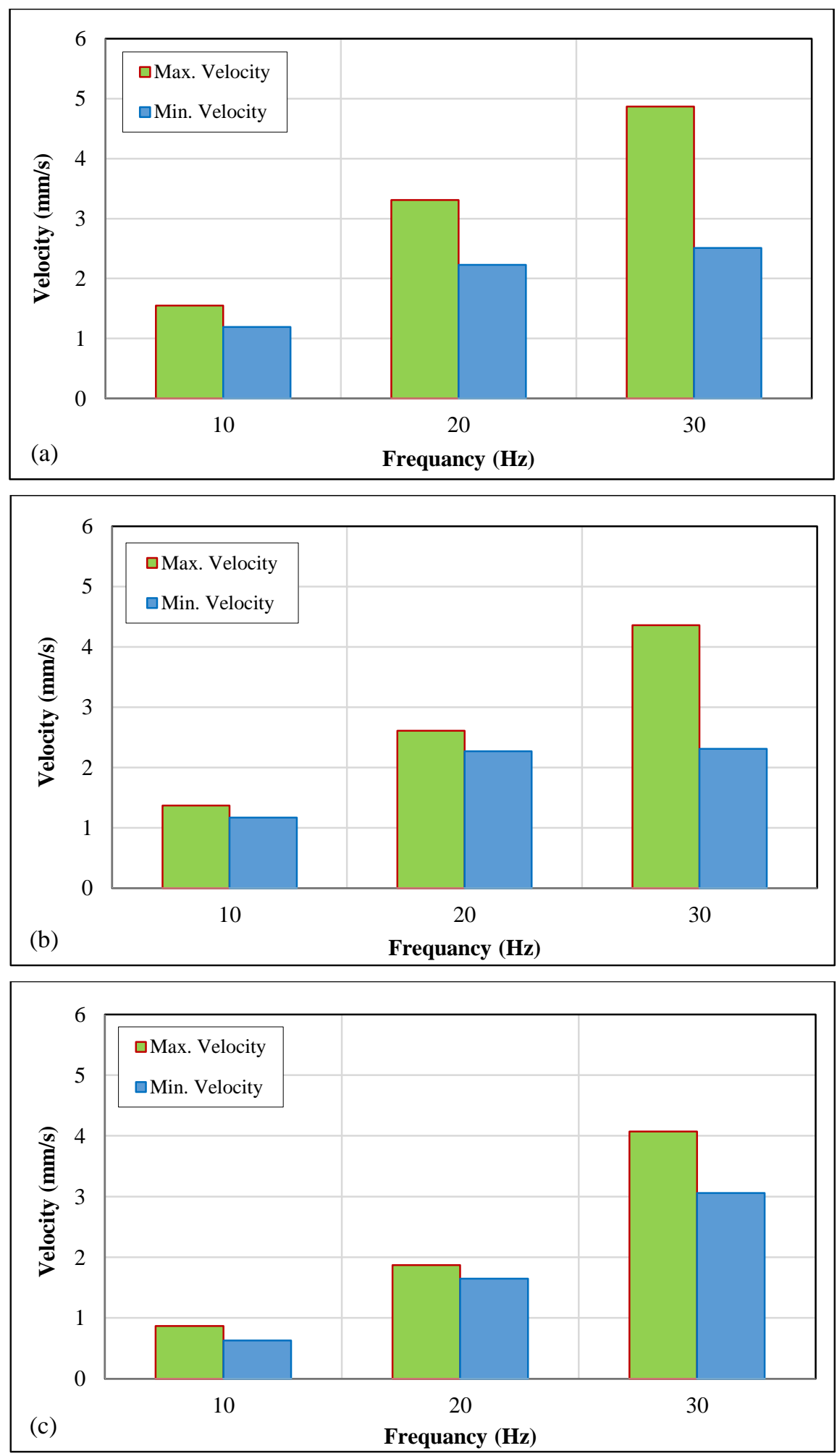

Figure 11. The velocity versus frequency for different spacing (s), (a) at $S=B$, (b) at $S=2 B$, (c) at $S=3 B$ for dry condition

The value of the velocity of the second footing increases with the increase the frequency of the first footing, on the other hand, the magnitude of the velocity decreased with increasing the spacing between the two footings, that's because the propagated of vibrations through the soil leads to a decrease in the energy of those vibrations and therefor decrease 
the velocity of vibrations. In addition, the value of velocity at dry state is greater than its value at soaked state, because of the presence of water in soil (whom acting as a wave inhibitor), causing decreasing in energy of vibration and that led to decrease in velocity of vibration for the second footing

As a result, it can mention the general remarks as followings:

- The velocity of vibrations at dry state greater than the velocity of vibrations at soaking state for all frequencies.

- The velocity of vibrations, increase when frequency increase, regardless whether the state is wet or dry.

- The velocity of vibrations reduced when the spacing between the two footings increase, in both soaked and dry specimen.
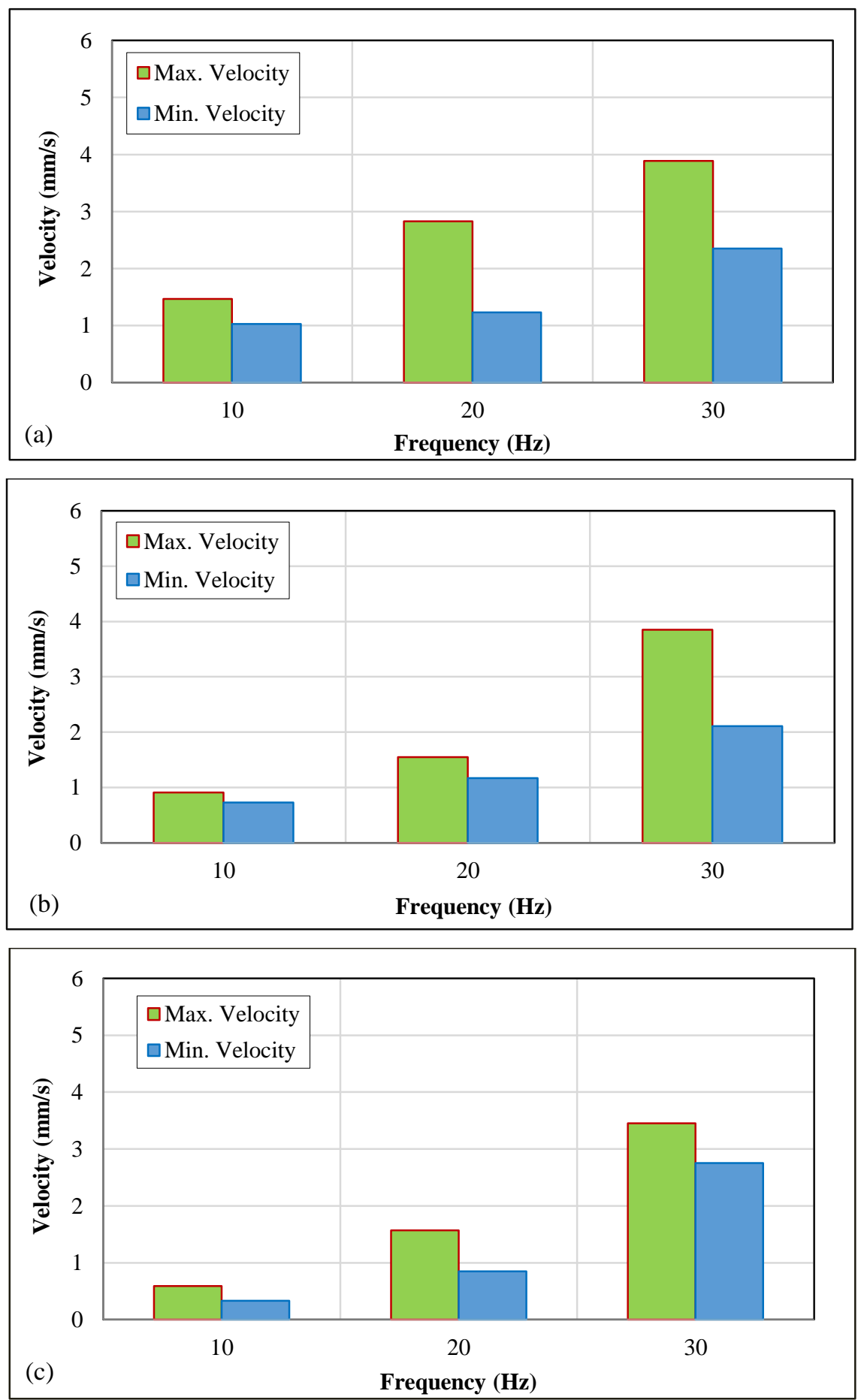

Figure 12. The velocity versus frequency for different spacing (s), (a) at $S=B$, (b) at $S=2 B$, (c) at $S=3 B$ for soaked condition

\subsection{The Acceleration}

The maximum and minimum acceleration versus the frequency are shown in Figures 13 and 14, which are recorded for three spacing of $(B)(S=B, S=2 B, S=3 B)$ for dry and soaked condition. the trend of behavior for maximum and 
minimum acceleration is similar in dry and soaked condition, it can be seen the value of the acceleration increases with increase the frequency in both state (dry and soaking) and decreases with increase the spacing between the footings. The effects of increasing the spacing between the footings on the magnitude of acceleration are similar to the effect on displacement amplitude and velocity, increasing the spacing led to decreases the acceleration, that's because the propagated of vibrations through the soil leads to a decrease in the energy of those vibrations (as mention earlier) and therefor decrease the acceleration. In addition, we observe the magnitude of the acceleration at dry state is greater than its value at soaked state.

At dry state, the maximum and minimum acceleration shows increases in magnitude of the acceleration almost linearly when goes from $10 \mathrm{~Hz}$ to $20 \mathrm{~Hz}$ or $30 \mathrm{~Hz}$, at spacing (1B). The same goes when spacing increase to (2B) and (3B). And here observed, the gap between the maximum and minimum increases when the frequency increase and the gap decreases when the spacing between the two footings increases. See Figure 13.
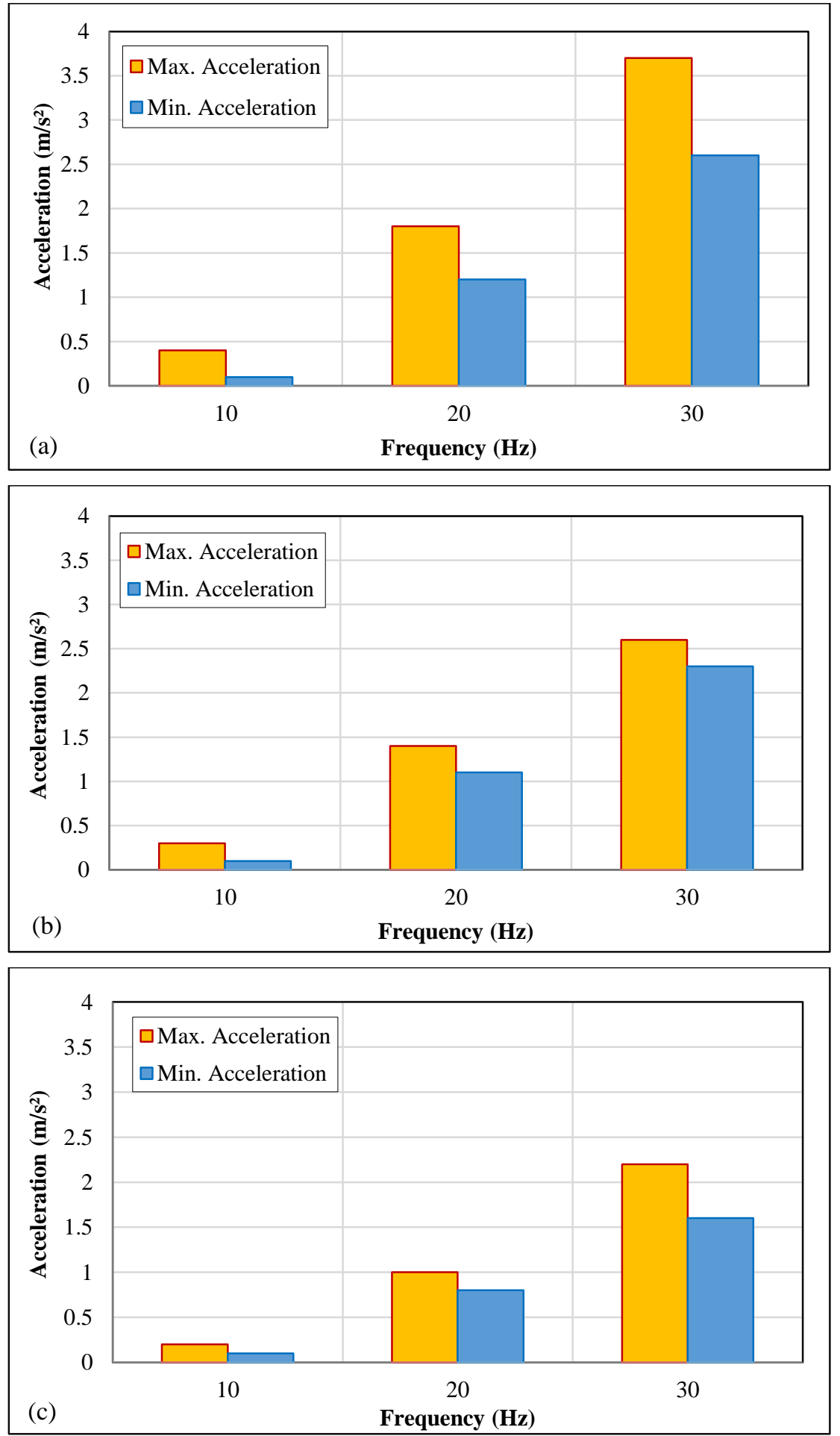

Figure 13. The Acceleration versus frequency for different spacing (s), (a) at $S=B,(b)$ at $S=2 B$, (c) at $S=3 B$ for dry condition 
At soaking state, for the maximum and minimum acceleration, the rate of increase in acceleration just slightly when goes form $10 \mathrm{~Hz}$ to $20 \mathrm{~Hz}$, but for $30 \mathrm{~Hz}$ is about higher than a double value, this applies to the magnitude of acceleration at a spacing of $1 \mathrm{~B}, 2 \mathrm{~B}$, and $3 \mathrm{~B}$. The gap between the maximum and minimum acceleration increases when increasing the frequency and decreases with increases the spacing between the two footings. The values of the acceleration at soaked state for three frequencies $(10,20,30) \mathrm{Hz}$ at spacing of $1 \mathrm{~B}, 2 \mathrm{~B}$, and $3 \mathrm{~B}$, recorded decreasing compared with their values at dry state because of the presence of water in soil whom acting as a wave inhibitor (as mentioned earlier), and it, increase when frequency increase, regardless whether the state is wet or dry. The acceleration reduced when the spacing between the two footings increase, in both soaked and dry specimen, see Figure 14.
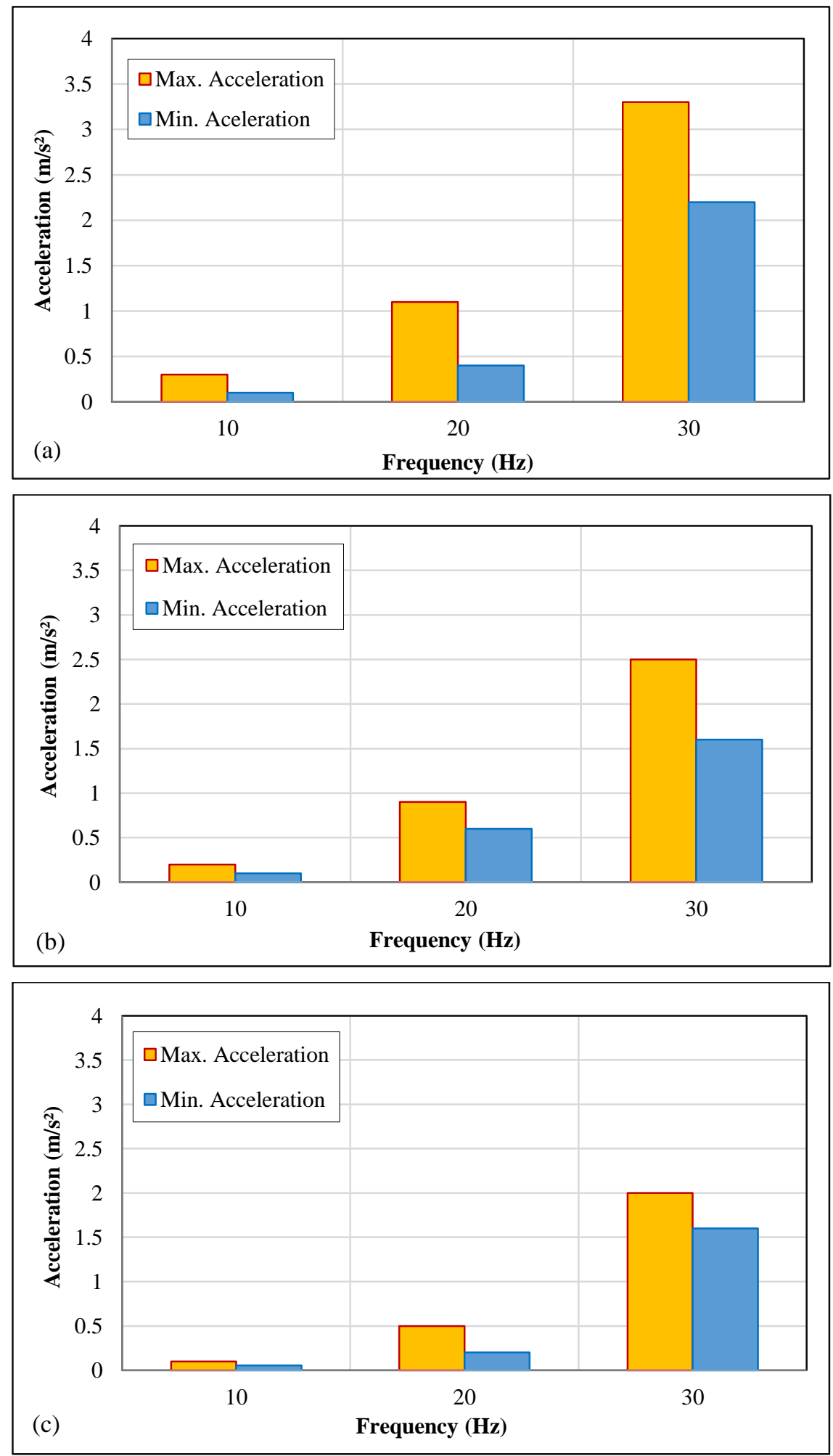

Figure 14. The Acceleration versus frequency for different spacing (s), (a) at $S=B,(b)$ at $S=2 B$, (c) at $S=3 B$ for soaking condition 


\section{Conclusions}

\subsection{Displacement Amplitude}

- The magnitude of displacement amplitude of the foundation under effect of dynamic load comes from adjacent foundation (both foundations erected on gypseouse soil) increases with increase the operation frequency.

- The value of amplitude at dry state is greater than its value at soaked state.

- The displacement amplitude decrease with increases the spacing between the two footings. The reduction in value of displacement amplitude when the spacing between the two footings increased from $1 \mathrm{~B}$ to $2 \mathrm{~B}$ at frequency of $10 \mathrm{~Hz}$ is $15.3 \%$ at dry state, and $21 \%$ at soaking state. and when the spacing increased from $1 \mathrm{~B}$ to $3 \mathrm{~B}$, the reduction is $44.6 \%$ and $52.9 \%$ at dry and soaking state respectively, at frequency of $20 \mathrm{~Hz}$, the displacement amplitude decreased by $(9.35 \%$ and $13.8 \%)$ at dry and soaking state respectively, when spacing increased from $1 \mathrm{~B}$ to $2 \mathrm{~B}$ and decreased by $(13.3 \%$ and $22.4 \%)$ at dry and soaking respectively, when spacing increased from $1 \mathrm{~B}$ to $3 \mathrm{~B}$. For the frequency of $30 \mathrm{~Hz}$, the reduction is $15.7 \%$ at dry state and $36.5 \%$ at soaking state when the spacing increased from $1 \mathrm{~B}$ to $2 \mathrm{~B}$, and when the spacing increased from $1 \mathrm{~B}$ to $3 \mathrm{~B}$, the displacement amplitude decreased by $(19 \%$ and $41.7 \%$ ) at dry and soaking condition respectively.

\subsection{Velocity of Vibrations}

- The velocity of vibrations of foundation (loaded with static weight) nearby another foundation which subjected to dynamic load (both foundations erected on gypseouse soil) increases with the augments of operation frequency.

- The magnitude of the velocity at dry state is greater than its value at soaked state

- The value of the velocity decreases with the increase of spacing between the two footings. The reduction in value of velocity of vibrations when the spacing between the two footings increased from $1 \mathrm{~B}$ to $2 \mathrm{~B}$ at frequency of 10 $\mathrm{Hz}$ is $11.6 \%$ at dry state, and $38 \%$ at soaking state. and when the spacing increased from $1 \mathrm{~B}$ to $3 \mathrm{~B}$, the reduction is $43.8 \%$ and $59.8 \%$ at dry and soaking state respectively, at frequency of $20 \mathrm{~Hz}$, the velocity of vibrations decreased by $(21.3 \%$ and $45 \%)$ at dry and soaking state respectively, when spacing increased from $1 \mathrm{~B}$ to $2 \mathrm{~B}$ and decreased by $(43 \%$ and $48.7 \%)$ at dry and soaking respectively, when spacing increased from 1B to 3B. For Frequency of $30 \mathrm{~Hz}$, the reduction is $2 \%$ at dry state and $1 \%$ at soaking state when the spacing increased from $1 \mathrm{~B}$ to $2 \mathrm{~B}$, and when the spacing increased from $1 \mathrm{~B}$ to $3 \mathrm{~B}$, the velocity of vibrations decreased by $(10 \%$ and $11.5 \%)$ at dry and soaking condition respectively.

\subsection{Acceleration}

- The acceleration of the foundation under effect of dynamic load comes from adjacent foundation on gypseous soil decreases with decreases the operation frequency.

- The value of the acceleration at soaking state is lower than its value at dry state.

- The value of the acceleration decreases with the increase of spacing between the two footings. The reduction in magnitude of acceleration when the spacing between the two footings increased from $1 \mathrm{~B}$ to $2 \mathrm{~B}$ at frequency of 10 $\mathrm{Hz}$ is $24 \%$ at dry state, and $30 \%$ at soaking state. and when the spacing increased from $1 \mathrm{~B}$ to $3 \mathrm{~B}$, the reduction is $51 \%$ and $59 \%$ at dry and soaking state respectively, at frequency of $20 \mathrm{~Hz}$, the acceleration decreased by $(22.2 \%$ and $18 \%)$ at dry and soaking state respectively, when spacing increased from $1 \mathrm{~B}$ to $2 \mathrm{~B}$, and decreased by $(45.1 \%$ and $54.5 \%$ ) at dry and soaking respectively, when spacing increased from $1 \mathrm{~B}$ to $3 \mathrm{~B}$. For Frequency of $30 \mathrm{~Hz}$, the reduction is $29.7 \%$ at dry state and $24.2 \%$ at soaking state when the spacing increased from $1 \mathrm{~B}$ to $2 \mathrm{~B}$, and when the spacing increased from $1 \mathrm{~B}$ to $3 \mathrm{~B}$, the acceleration decreased by $(32.4 \%$ and $27.3 \%)$ at dry and soaking condition respectively.

\section{Acknowledgement}

I would like to express deep gratitude to my supervisor Assist. Prof. Dr. Waad A. Zakaria for encouragement and significant suggestions, which improved this work. So, I'm greatly indebted to him. Appreciation and thanks are also extended to the all staff of Civil engineering department, and the staff of Soil Mechanics Laboratory, Diyala University, Iraq.

\section{Conflicts of Interest}

The authors declare no conflict of interest.

\section{References}

[1] Gazetas, George. "Formulas and charts for impedances of surface and embedded foundations." Journal of geotechnical engineering 117, no. 9 (1991): 1363-1381. doi:10.1061/(ASCE)0733-9410(1991)117:9(1363). 
[2] Rao, NSV Kameswara. Vibration analysis and foundation dynamics. Wheeler Publishing, (1998).

[3] Kameswara Rao, N. S. V. "Foundation Design” (December 10, 2010). doi:10.1002/9780470825365.

[4] Tham, L.G., J. Qian, and Y.K. Cheung. "Dynamic Response of a Group of Flexible Foundations to Incident Seismic Waves." Soil Dynamics and Earthquake Engineering 17, no. 2 (February 1998): 127-137. doi:10.1016/s0267-7261(97)00021-3.

[5] Ghosh, Priyanka, and Rajusha Kumari. "Seismic Interference of Two Nearby Horizontal Strip Anchors in Layered Soil." Natural Hazards 63, no. 2 (April 25, 2012): 789-804. doi:10.1007/s11069-012-0187-4.

[6] Ghosh, Priyanka. "FLAC Based Numerical Studies on Dynamic Interference of Two Nearby Embedded Machine Foundations." Geotechnical and Geological Engineering 30, no. 5 (June 16, 2012): 1161-1181. doi:10.1007/s10706-012-9530-5.

[7] Razouki, S. S., R. R. Al-Omari, I. H. Nashat, H. F. Razouki, and S. Khalid. "The problem of gypsiferous soils in Iraq." In Proceeding of the Symposium on Gypsiferous Soils and Their Effect on Structures, NCCL, pp. 7-33. 1994.

[8] Nashat, Isam H. "Engineering characteristics of some gypseous soils in Iraq." Unpub. Ph. D. Thesis. University of Baghdad (1990).

[9] Chen, Lin. “Dynamic Interaction Between Rigid Foundations on Multi-Layered Stratum.” Journal of Earthquake Engineering 20, no. 4 (November 24, 2015): 505-534. doi:10.1080/13632469.2015.1104746.

[10] Swain, Abhijeet, and Priyanka Ghosh. "Experimental Study on Dynamic Interference Effect of Two Closely Spaced Machine Foundations.” Canadian Geotechnical Journal 53, no. 2 (February 2016): 196-209. doi:10.1139/cgj-2014-0462.

[11] Chen, Lin. "Dynamic Interaction Between Rigid Surface Foundations on Multi-Layered Half Space." International Journal of Structural Stability and Dynamics 16, no. 05 (June 2016): 1550004. doi:10.1142/s0219455415500042.

[12] Sbartai, Badreddine. “Dynamic Interaction of Two Adjacent Foundations Embedded in a Viscoelastic Soil.” International Journal of Structural Stability and Dynamics 16, no. 03 (April 2016): 1450110. doi:10.1142/s0219455414501107.

[13] Keawsawasvong, Suraparb, and Teerapong Senjuntichai. "Dynamic Response of Two Rigid Foundations on Multi-Layered Poroelastic Medium." IOP Conference Series: Materials Science and Engineering 269 (November 2017): 012047. doi:10.1088/1757-899x/269/1/012047.

[14] Han, Zejun, Gao Lin, and Jianbo Li. "Dynamic 3D Foundation-Soil-Foundation Interaction on Stratified Soil.” International Journal of Structural Stability and Dynamics 17, no. 03 (April 2017): 1750032. doi:10.1142/s0219455417500328.

[15] Ali, O. S., and Mustafa Mahamid. "Dynamic Response of a Four-Cylinder Compressor Foundation Considering the Effect of Soil-Foundation Interaction-A Case Study.” Structures Congress 2018 (April 17, 2018). doi:10.1061/9780784481332.047.

[16] Vicencio, Felipe, and Nicholas A. Alexander. "Dynamic Interaction Between Adjacent Buildings through Nonlinear Soil During Earthquakes.” Soil Dynamics and Earthquake Engineering 108 (May 2018): 130-141. doi: 10.1016/j.soildyn.2017.11.031.

[17] Andersen, Lars Vabbersgaard. "Dynamic Soil-structure Interaction of Polypod Foundations.” Computers \& Structures (October 2018). doi: 10.1016/j.compstruc.2018.07.007.

[18] Keawsawasvong, S., T. Senjuntichai, R. Plangmal, and W. Kaewjuea. "Rocking Vibrations of Rigid Foundations on MultiLayered Poroelastic Media.” Marine Georesources \& Geotechnology (May 15, 2019): 1-13. doi:10.1080/1064119x.2019.1597229.

[19] Fattah, Mohammed Y., Mosa J. Al-Mosawi, and Abbas F.I. Al-Ameri. "Vibration Response of Saturated Sand - Foundation System.” Earthquakes and Structures 11, no. 1 (July 25, 2016): 83-107. doi:10.12989/eas.2016.11.1.083.

[20] Hassan, Falah, and Salwan Ahmed. "Dynamic Response of Machine Foundation Resting on Sand-Granulated Tire Rubber Mixtures.” Edited by T.S. Al-Attar, M.A. Al-Neami, and W.S. Abdul Sahib. MATEC Web of Conferences 162 (2018): 01021. doi:10.1051/matecconf/201816201021.

[21] Pradhan, P. K., A. Mandal, D. K. Baidya, and D. P. Ghosh. "Dynamic Response of Machine Foundation on Layered Soil: Cone Model Versus Experiments." Geotechnical and Geological Engineering 26, no. 4 (March 22, 2008): $453-468$. doi:10.1007/s10706-008-9181-8.

[22] Wersäll, Carl, and Stefan Larsson. "Small-Scale Testing of Frequency-Dependent Compaction of Sand Using a Vertically Vibrating Plate.” Geotechnical Testing Journal 36, no. 3 (March 21, 2013): 20120183. doi:10.1520/gtj20120183.

[23] Fattah, Mohammed Y., Mosa J. Al-Mosawi, and Abbas F. I. Al-Ameri. "Dynamic Response of Saturated Soil - Foundation System Acted Upon by Vibration.” Journal of Earthquake Engineering 21, no. 7 (September 16, 2016): 1158-1188. doi:10.1080/13632469.2016.1210060.

[24] Zakaria, Waad A., Qasim, A. Aljanabi, Othman, M. Ibrahim. "Effect of Vibration Load on Leaching Process for Sandy Gypseous Soil”, Electronic Journal of Geotechnical Engineering, Vol. 22 (2017), Bund. 12. 